\title{
The Influence of External Factors on the Development of Small and Medium Businesses in the Russian Federation
}

\author{
Inna Baranova and Maria Vlasenko* \\ Novosibirsk State Technical University, Department of Audit, Accounting and Finance, 630073, \\ Novosibirsk, Russia
}

\begin{abstract}
The development of small and medium-sized businesses, shaping the market structure of the economy, ensures the growth of production of goods and services, their saturation of the market, and solves a number of social problems. Under certain prerequisites, small and medium-sized businesses can become a driver of sustainable economic development and an increase in the "stratum" of the middle class, which predetermines its state support. Despite the importance of SMEs for the national economy, this sector of the economy remains the most vulnerable and subject to the influence of the external environment. For example, many small companies, which traditionally have weak immunity to negative market fluctuations, barely withstood the impact of the COVID-19 pandemic. As part of the study, an assessment of the influence of external factors on the volume of activities of small and medium-sized businesses in the Siberian Federal District was given, monitoring and timely response to changes in which will allow managing to provide timely support for small businesses.
\end{abstract}

\section{Introduction}

Support for the development of small businesses is one of the priority areas of government policy in all countries.

The development of small and medium-sized enterprises (SMEs) in various countries has become a powerful lever for solving a complex of political, financial, economic and social problems, which manifested itself in the formation of a progressive structure of the economy and a competitive environment; expanding the taxable base for budgets of all levels; increasing gross domestic product; reducing the level of unemployment and ensuring employment of the population; saturation of the market with a variety of goods and services [1,2].

In the context of an active transformation of socio-economic processes, the practice of state support for small businesses in Russia and abroad is constantly developing and improving, reflecting not only the new needs for the development of SMEs, but also the existing nature of the market economic system, levers of state regulation, and digitalization of the economy. SMEs are actively involved in the digital transformation of the economy, which opens up new

* Corresponding author: vma-1991@yandex.ru 
opportunities for innovation and prosperity associated with the use of new digital technologies to transform their business models and working methods. Digital business platforms facilitate access to markets, strategic resources and networks, reducing the associated costs for SMEs. At the same time, the paradox of the digital economy is the ambivalent role of SMEs: on the one hand, it acts as a generator of revolutionary technological breakthroughs, and on the other hand, it significantly lags behind in digitalization of services [1].

In different countries of the world, authorities and administrations ambiguously assess the role of SMEs and, with varying degrees of activity, support this segment of business, which has given rise to a variety of forms and directions of state support for SMEs as factors of their development. Globally, SMEs face external factors such as disproportionately high barriers to funding; the market does not adequately recognize the role of SMEs: the specific, undiversified investment risk is too high.

Despite the importance of SMEs for the national economy, this sector of the economy remains the most vulnerable and subject to the influence of the external environment. The lockdown caused by the COVID-19 pandemic showed that it is very difficult for SMEs to adapt to external changes, a change in the work format. This fact determines the study of the influence of external factors on the activities of SMEs and the identification of the most significant among them, which will make it possible to make adjustments to the ongoing state support for SMEs.

The pandemic and the new coronavirus infection have had a dramatically negative impact on the state of SMEs. As shown by the results of a study by the Higher School of Economics [3], SMEs working in the retail trade and construction sector suffered the most in the Russian Federation. So, for example, the retail trade turnover of small businesses in the 1st half of 2020 decreased by 343.9 billion rubles. compared to the same period of the previous year, or $10 \%$. The share of small enterprises in the total retail trade turnover in the 1st half of 2020 also decreased by $1.4 \%$ compared to the same period in 2019 . Small construction companies, traditionally having weak immunity to negative market fluctuations, could hardly withstand the pandemic the onslaught of force majeure.

\section{Literature review}

The economic literature presents various factors influencing the development of small business. At the same time, it was revealed that the functioning of SMEs in Russia and abroad significantly differ from each other even in the context of the development factors themselves.

Foreign researchers J. Ukko, M. Saunila, J. Havukainen within the framework of sustainable development distinguish: environmental aspects (waste management, environmental factors, energy consumption, etc.); social aspects (public recognition, job creation, human capital development, etc.); economic aspects (cost reduction, income, etc.) [4].

V. Matinaro, Y. Liy, T-R. Lee, J. Poesche propose factors of a sustainable business model for SMEs, which are based on the general principles of sustainable development. The economic aspects of the factors of a sustainable business model take into account high financial results, development of competitiveness, increased business activity, etc. Social aspects include corporate value, impact on the organization's reputation, and relationships within the team. Environmental aspects are to improve and protect the environment [5].

Cook P., Ou C., Haynes G. W. One of the main factors in the development, growth and success of SMEs is the availability of financing [6,7]. A number of foreign researchers identify sub-factors affecting the availability of financing for SMEs. P. Quartey [8] notes as a factor the age of a small business, which affects the ability to access external financing. O. Fatoki, F. Asah, Abor J. $[9,10]$ focus on the geographic location of SMEs, for example, their location near banks gives advantages in strengthening informal relations with creditors. Irwin D., Scott J. M. note 
the personality of the owner-manager as a factor affecting the firm's ability and the likelihood of gaining access to external financial resources [11]. N. Mijid [12] S. Coleman [13] identified a gender factor and provided evidence of credit discrimination against women entrepreneurs.

A.N. Berger, G.F. Udell [14] believe that the lack of transparency of information is a serious enough problem for the development of SMEs.

Russian researcher S.T. Adelshanov expands the factors of sustainable development of SMEs, highlighting: socio-economic (government support, availability of investment funds, interaction of economic and social infrastructure at all levels of the economy); legislative consistency; economic freedom; innovative activity of the entrepreneurial sector, noting that "at present, Russian small and medium-sized businesses are not characterized by high innovative activity - no more than $5 \%$ of organizations in this institutional segment carry out marketing, technological, and managerial innovations" [15].

S.A. Kucheryavenko in the system of risk management in the activities of SMEs distinguishes economic (market and technological), climatic, political, socio-cultural, production and non-production factors [16]. The proposed grouping, on the one hand, is classic, and on the other hand, it includes a fairly wide range of factors.

It should be noted that foreign researchers associate the development of SMEs with the application of the concept of corporate social responsibility within each SME entity, while Russian scientists see the development of SMEs in an increase in the already broad measures of state support.

\section{Review of the activities of small and medium-sized businesses}

Opposition to factors of external and internal environment is the basis for sustainable development of small and medium-sized organizations. According to the data of the global monitoring of entrepreneurship [17], the following factors have been identified that limit the activities of SMEs (Fig. 1).

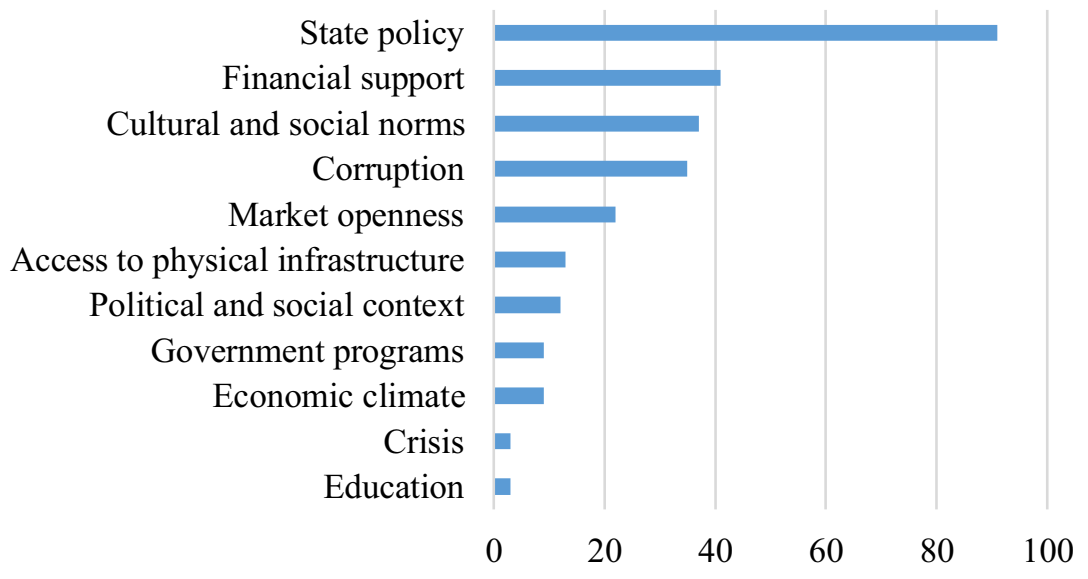

Source [18].

Fig. 1. Factors that have a restraining effect on the development of small and medium-sized businesses in the Russian Federation

The main factors limiting the activities of SMEs (Fig. 1) are government policies, financial support, cultural and social norms, and corruption. In a turbulent environment, SMEs are subject 
to the influence of external factors to a greater extent than large organizations, since they do not have the reserves that large organizations have.

In 2020, the COVID-19 pandemic became the main destabilizer of the global economy. In the report of B. Titov, Commissioner for the Protection of the Rights of Entrepreneurs, it was noted that in the spring of 2020,53.3\% of SMEs described their situation as a "crisis" and "catastrophe"; $62.2 \%$ assessed the chance of survival below $50 \%$. By the summer of 2020 , activity was suspended for $35.7 \%$ of companies $(56.1 \%$ of companies were not working at the peak of quarantine); $55.6 \%$ of companies noted that demand decreased by $50 \%$ or more. Key difficulties - inability to pay wages $(52.4 \%)$, rent and property tax $(42.8 \%)$; the majority of companies did not lay off employees, but reduced the payroll $(60.88 \%)$ and sent employees on vacation at their own expense (57.6\%) [19].

According to RBC, by the end of $202,62 \%$ of respondents felt the negative impact of the COVID-19 pandemic on business, while $21 \%$ noted the positive impact of the introduced lockdown. The factors of negative influence on the activities of companies were restrictive measures on the work of organizations and the movement of employees, a decrease in consumer demand, a change in the consumer model of the population and a depreciation of the ruble [20].

The pandemic had a strong impact on SMEs and abroad, for example, in the United States in the first four months of 2020, 98 enterprises with debt of more than \$50 million declared bankruptcy [21], by September 2020, 20\% of US small enterprises went bankrupt [22]. At the beginning of 2020, Chinese SMEs also experienced problems related to the lockdown on COVID-19, however, timely government support and its own reserve funds made it possible to quickly restore the activities of SMEs and the economy as a whole. At the end of 2020, China demonstrated a GDP growth of $2.3 \%$ [23].

Practice has shown that during the crisis, the importance of measures of state support for SMEs increases. According to the World Bank, the main instruments of state support for SMEs are debt financing and employment support.

In 2020, the Russian Federation equally applied debt financing, employment support and tax incentives to support SMEs.

The main indicator characterizing the activities of SMEs is their turnover. To identify the factors influencing the turnover of SMEs, an assessment of its structure in the Siberian Federal District was carried out (Fig. 2).

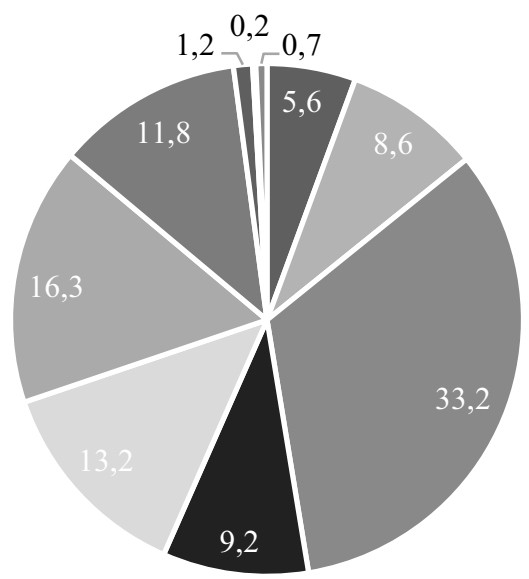
- Tomsk region
- Omsk region
- Novosibirsk region
- Kemerovo region
Irkutsk region
- Krasnoyarsk region
- Altai region
- The Republic of Khakassia
- Tyva Republic
- Altai Republic

Fig. 2. Structure of small and medium-sized businesses turnover in the Siberian Federal District in $2019, \%$

Compiled according to [18] 
The main turnover of SMEs in the Siberian Federal District falls on the Novosibirsk Region (33.2\%), the Krasnoyarsk Territory (16.2\%) and the Irkutsk Region (13.2\%), which is explained by the high profitability and investment attractiveness of the regions.

\section{Research results}

Taking into account the factors considered and the above overview of the SME sector, the external factors influencing the turnover of SMEs in the Siberian Federal District are highlighted (Table 1).

Table 1. External factors affecting the turnover of small and medium-sized businesses in 2019.

\begin{tabular}{|c|c|c|c|c|c|}
\hline title & 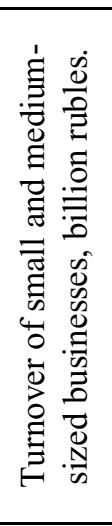 & 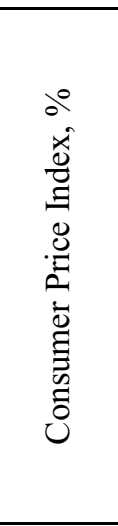 & 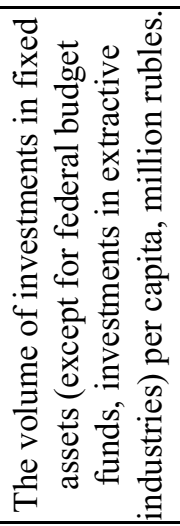 & 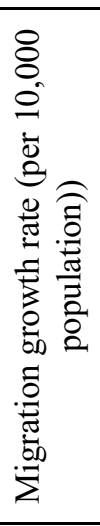 & 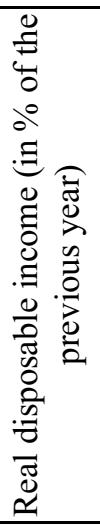 \\
\hline Altai Republic & 40,5 & 101,95 & 21027 & 25,4 & 101,9 \\
\hline Tyva Republic & 11,7 & 103,31 & 18915 & $-11,7$ & 103,2 \\
\hline The Republic of Khakassia & 68,6 & 103,44 & 32661 & $-14,5$ & 99,5 \\
\hline Altai region & 652,5 & 103,28 & 112771 & $-17,9$ & 99,6 \\
\hline Krasnoyarsk region & 898,6 & 103,83 & 436407 & $-9,7$ & 100,6 \\
\hline Irkutsk region & 731,6 & 104,08 & 366724 & $-13,7$ & 101,7 \\
\hline Kemerovo region & 512,4 & 103,89 & 288407 & $-9,4$ & 101,1 \\
\hline Novosibirsk region & 1841,3 & 102,93 & 247429 & 37,1 & 101,6 \\
\hline Omsk region & 474,5 & 103,55 & 172267 & $-62,2$ & 100,2 \\
\hline Tomsk region & 309,5 & 103,84 & 101716 & 30,3 & 98,9 \\
\hline
\end{tabular}

Source [18].

The factors presented in Table 1 have the following impact on the activities of SMEs: the growth of consumer prices, reducing the real income of SMEs, predetermines the need to improve production technology, expand the range of goods and services. The largest increase in prices is observed in the Irkutsk region (4.08), in the Tomsk region (3.84) and in the Krasnoyarsk region (3.89), which is higher than the average for Russia (3.04) and the Siberian Federal District (3.58).

The volume of investments in fixed assets is one of the positive factors in the development of SMEs, contributing to the growth in the volume of their activities. Irkutsk Oblast and Krasnoyarsk Krai are the leaders in terms of investments in fixed assets in the Siberian Federal District.

The migration movement of the population affects labor resources in the regions of the Siberian Federal District. In general, there is a migration outflow in the Siberian Federal District, 
with the exception of the Novosibirsk region, the Tomsk region and the Altai Republic, which are characterized by migration growth.

The volume of average wages also affects the activities of SMEs, since, on the one hand, these are the costs of the organization, and on the other, it is a tool to stimulate employees to work more efficiently and increase labor productivity.

In order to determine the influence of factors on SME turnover, a regression analysis was carried out (Table 2).

Table 2. Regression analysis of the influence of external factors on the turnover of small and mediumsized businesses

\begin{tabular}{|l|c|c|c|c|c|c|}
\hline \multicolumn{1}{|c|}{ Factors } & Odds & $\begin{array}{c}\text { Standard } \\
\text { error }\end{array}$ & $\begin{array}{c}t- \\
\text { statistic } \\
s\end{array}$ & $\begin{array}{c}P- \\
\text { Value }\end{array}$ & $\begin{array}{c}\text { Lower } \\
95 \%\end{array}$ & $\begin{array}{c}\text { Upper } \\
95 \%\end{array}$ \\
\hline Y-intersection & $\begin{array}{c}33851, \\
0\end{array}$ & 46886,5 & 0,722 & 0,503 & $-86674,6$ & 154376,5 \\
\hline $\begin{array}{l}\text { Consumer price index, } \\
\%\end{array}$ & $-279,1$ & 384,4 & $-0,726$ & 0,500 & $-1267,3$ & 709,0 \\
\hline $\begin{array}{l}\text { Per capita investment in } \\
\text { fixed assets, RUB mln }\end{array}$ & 0,003 & 0,001 & 2,177 & 0,081 & $-0,001$ & 0,007 \\
\hline $\begin{array}{l}\text { Migration growth rate } \\
\text { (per } \\
\text { population),\% } \%, 000\end{array}$ & 4,609 & 6,213 & 0,742 & 0,492 & $-11,363$ & 20,580 \\
\hline $\begin{array}{l}\text { Real disposable } \\
\text { income, } \% \text { of the } \\
\text { previous year, }\end{array}$ & $-49,2$ & 136,5 & $-0,360$ & 0,733 & $-399,959$ & 301,616 \\
\hline
\end{tabular}

Regression analysis of the relationship between SME turnover and external factors showed that the main factor influencing SME turnover is the consumer price index: an increase in the consumer price index, reducing purchasing demand, leads to a decrease in SME turnover by 279.1 million rubles. A strong influence is exerted by the level of real disposable income of the population, whose growth by $1 \%$ will lead to a decrease in turnover by 49.2 million rubles; coefficient of migration growth: as a result of its increase by $1 \%$, the turnover of SMEs will increase by 4.6 million rubles. The volume of investments in fixed assets has an insignificant effect on the turnover of SMEs: their growth by 1 thousand rubles. will lead to an increase in SME turnover by 3 thousand rubles.

\section{Conclusion}

The conducted research, domestic and foreign practice have shown that the importance of SMEs cannot be underestimated, which, under certain prerequisites, can become a driver of sustainable economic development and an increase in the "stratum" of the middle class. For the successful functioning of SMEs, states create favorable conditions, providing guarantees of stability and confidence of entrepreneurs in support from the state.

The study confirmed the significant dependence of the activities of SMEs on external factors, monitoring and timely response to changes in which will allow to manage the volume of activities of SMEs and provide timely support. 


\section{References}

1. I. V. Baranova, M. A. Vlasenko, E. V. Kostyaeva, P. N. Teslya, Financial support for small and medium-sized businesses in the context of the digitalization of the economy. (NSTU Publishing House, Novosibirsk, 2020).

2. I. V. Baranova, M. A. Vlasenko, Sustainable Development of the Digital Economy, industry and innovation systems (Sat. tr. scientific-practical conf. with a foreign study, PolytechPress, St. Petersburg, 2020, Pp. 424-426).

3. I.S. Lola, Business Activity and Prospects for the Development of Small Enterprises in Russia in the Conditions of Coronacrisis (NRU HSE, Moscow, 2020).

4. J. Ukko, Sustainable Development, 27 (2019).

5. V. Matinaro, Journal of Cleaner Production, 209 (2019).

6. P. Cook, Journal of Developmental Entrepreneurship, 6(1) (2001).

7. C. Ou, G. W. Haynes, Small Business Economics, 27(2) (2006).

8. P. Quartey, Journal of African Business, 4(1) (2003).

9. O. Fatoki, F. Asah, International Journal of Business and Management, 6(8) 2011.

10. J. Abor, African Economic Research Consortium (2008).

11. D. Irwin, J. M. Scott, International Journal of Entrepreneurial Behaviour and Research, 16(3) (2010).

12. N. Mijid, PhD thesis, Colorado State University (2009).

13. S. Coleman, The Role of Human and Financial Capital in the Profitability and Growth of Women-Owned, (2007).

14. A. N. Berger, G. F. Udell, Journal of Banking and Finance, 22 (1998).

15. S.T. Adelshanov, North Caucasus: spatial development and human capital (Materials following the results of the work of the discussion platforms of the International Forum held for young scientists, graduate students, undergraduates and students, 2018. - pp. 1419).

16. S.A. Kucheryavenko, Socio-economic development of organizations and regions of Belarus: efficiency and innovation (Materials of reports of the International Scientific and Practical Conference, Vitebsk State Technological University, 2017. S. 222-228).

17. Global Entrepreneurship Monitor 2019-2020. https://gsom.spbu.ru/images/cms/menu/otchet_2020-red-2n-04-06.pdf

18. Federal State Statistics Service - URL: https://rosstat.gov.ru/ (date of treatment 07/05/2020).

19. Appendix to the report of the President of the Russian Federation "COVID-19: Consequences for Business and Economy". - URL: https://www.garant.ru/files/5/8/1376885/doklad_bizness_ombudsmen_covid_19.pdf (date of treatment 07/05/2020).

20. Research on the impact of the CJVID-19 pandemic on the Russian market. URL: https://sapmybiz.rbc.ru/RBK_Issledovanie_vliyaniya_pandemii_COVID_19_na_rossiysk iy_biznes.pdf

21. Bloomberg: The pandemic has contributed to a record number of major bankruptcies in the United States. - URL: https://tass.ru/ekonomika/8594183.

22. NBC: in the US, small business is barely afloat due to coronavirus. - URL: https://russian.rt.com/inotv/2020-12-02/NBC-v-SSHA-malij-biznes/.

23. China has overcome the crisis and has shown growth. How can Russia adopt this experience? - URL: https://svpressa.ru/world/article/287666/. 